\title{
ON THE PROBLEMATIC OF „RESEARCH ISLANDS" (PART 1)
}

\author{
Milan Kubiatko \\ Masaryk University, Brno, Czech Republic \\ E-mail: mkubiatko@gmail.com
}

This problematic concerns only countries in middle Europe, because the author does not know the situation in countries from Western Europe or from far countries like USA or Australia. A very general division consists in two types of researchers. Researchers from the first type relatively do not like researchers from the second type and vice versa. The first type of researchers is people, whose work does not exceed the boundaries of the native country. Their publishing outcomes are predominantly contributions in the local proceedings of a conference. The value of these kinds of contributions is relatively very low and in some cases the contributions are without any value. This situation is caused by the fact that the conference organizers accept every contribution without any review process. The style of conferences has been still the same for many years, i.e. the oral and poster section and next acceptance of all contributions to local proceedings. The new style of conference organization is very rare in the conditions of the Middle Europe country, where discussion forums and contributions are offered to some international journal. This situation is very advantageous for the majority of academicians; they have got a published contribution, where the revisions are not necessary. So, some of this academicians are trying to publish own results in the local journals, where the review process is presented, usually two reviews per one manuscript. This is a better effort than to send manuscripts to the proceedings of the conference. The value of contributions is higher, but the impact of the journal and papers of course as well is only local. But in the case of local journals is very interesting, for many academicians unimaginable, that contributors are often editors in chief and also members of the editorial board. From my point of view, it is an incorrect process. Editors and editorial board members cannot be authors of articles in the journal where they are editors and editorial board members. There are two possible reasons, why it is so. The first one lies in the low amount of manuscripts from the other academicians. But, it is a little bit unbelievable; I give an example from my own experience. In the year 2011 I sent a manuscript to one local journal, the review process ran with a positive result, but the editor sent me a statement that my manuscript would be published in the year 2013, because they had got a huge amount of accepted manuscripts. So, the most probable reason is that the editor and members need publishing outcomes and it is an easy way to have some article. However, relative danger is in this form of the publication process, the blind review does not exist, because the editor knows, who the reviewer is and the editor has got a possibility to influence the choice of reviewers and this all leads to decreasing of the quality of the publication outcomes. Other groups of authors are friends of the editor or some member of the editorial board, so the editor in many cases is trying to meet the other authors and their publication is published many times with a lower quality. This effect is probably caused by the relatively low amount of researchers in the problematic of educational research and the effect "everybody knows everybody" brings the outcomes. The authors have got a lot of publications and they are relatively successful, but the impacts are only local, from one boundary to another, and it all resonates with an island where local authors are islanders. Their effort to publish some study in an international journal is limited by unfamiliarity of the review process and maybe of fear of the rejection of their manuscript.

On the other side are standing the researchers who transcend the boundaries of the na- 
Milan KUBIATKO. On The Problematic Of „Research Islands" (Part 1)

PROBLEMS

OF EDUCATION

IN THE $21^{\text {st }}$ CENTURY

Volume 53, 2013

tive country and they have no restraints to send their manuscript to an internationally reputable journal (no one) and lead a long fight with a happy end with the reviewers. But, their success is only relative, it is only own intrinsic satisfaction with own hard work. The number of this kind of authors (called "seafarers") is very low in comparison with "islanders" and it aims to a very interesting situation. The "seafarers" are less reputable and the top scientists are "islanders". The next interesting thing is that the "seafarers" bring more money to faculties, because the policy says more valuable are international publications than local, but the dividing of money is inequitable, because in many cases are publications equal without regard if the publication was included in the Web of Science or if it is only local, though "seafarers" brings several times more money and credit to the department or faculty like "islanders". So, we can be proud of an enthusiastic approach of a couple of people who run against the wind and we can hope, the situation with the appreciation with this kind of people will change in the future, because we will still live on a research island surrounded by the sea.

Received: April 21, 2013

Accepted: April 25, 2013

Milan Kubiatko

$\mathrm{PhD}$, Assistant Professor at Department of Education at Faculty of Education, Masaryk University in Brno, Czech Republic.

E-mail: mkubiatko@gmail.com

Website: http://www.kubiatko.eu/ 